\title{
Las lenguas indígenas de la Costa Rica actual
}

\author{
J. Diego Quesada \\ Universidad Nacional (Costa Rica)
}

Según el último censo sobre población indígena que se realizó en Costa Rica (Solano 2000), y que cubrió los 22 territorios indígenas del país, la población indígena costarricense se compone de 8 pueblos indígenas, distribuidos de la siguiente manera:

La población indígena, según el censo, asciende a un total de 63,876 personas, lo que corresponde a un $1.7 \%$ de la población del país. Solo un $42.3 \%$ de la población vive dentro de esos territorios; un $18.2 \%$ vive en la periferia de los territorios y el

\begin{tabular}{|l|l|l|}
\hline ETNIA & TERRITORIOS & PROVINCIA(S) \\
\hline Huetar & Quitirrisí y Zapatón & San José \\
\hline Guatusa & Guatuso & Alajuela \\
\hline Chorotega & Matambú & Guanacaste \\
\hline Bribri & $\begin{array}{l}\text { Salitre, Cabagra/Talamanca Bribri y y } \\
\text { Kekoldi Cocles }\end{array}$ & Puntarenas/Limón \\
\hline Cabécar & $\begin{array}{l}\text { Alto Chirripó, Tayni, Talamanca Cabécar, } \\
\text { Telire, Bajo Chirripó/Nairi Awari/Ujarrás }\end{array}$ & $\begin{array}{l}\text { Limón/Cartago/ } \\
\text { Puntarenas }\end{array}$ \\
\hline Boruca & Boruca y Rey Curré & Puntarenas \\
\hline Guaymí & $\begin{array}{l}\text { Abrojo Montezuma, Coto Brus, Conte } \\
\text { Burica y Osa }\end{array}$ & Puntarenas \\
\hline Teribe & Térraba & Puntarenas \\
\hline
\end{tabular}
restante $39.5 \%$ vive en el resto del país (Solano 2000: 348). En cuanto a la distribución de la población que vive en sus territorios, por etnia, las cantidades son las siguientes: huetares 1006, guatusos 460, chorotegas 868 , bribris 9,645 , cabécares 9861 , borucas 2017 , guaymíes 2563, teribes 621, para un total de 27,041. La distribución de estas etnias se ilustra en el Mapa 1.

El censo no da cuenta de la etnia buglé, grupo indígena que, junto con el guaymí, es originario de Panamá y que por migración relativamente reciente (no más de 50 años) se encuentra en el país. Los buglés son aproximadamente 200 y viven en estrecho contacto con los guaimíes. Esta cercanía geográfica ha existido desde tiempos inmemoriales. Mucho antes de la creación de las reservas indígenas en Panamá, en los años 60 y 70, los buglés ya habían

iniciado su diáspora, dejando la provincia de Veraguas en dirección a la de Bocas del Toro y posteriormente a la de Chiriquí donde muchos se dispersaron. Dado que Chiriquí ha sido hasta la actualidad territorio guaymí, esa dispersión los llevó a un proceso de asimilación a la cultura guaymí. No es de extrañar por ello que se les haya confundido y hasta denominado guaymí sabaneros en oposición a buglés. Ya asimilados, o casi asimilados, los buglés iniciaron otra migración, esta vez hacia Costa Rica y se han asentado junto con los guaymíes en Limoncito, Coto Brus (Puntarenas); el motivo de esa migración conjunta con los guaymíes no está del todo claro. Por esta razón, si es que los buglés no fueron censados, entonces existe la posibilidad de que en el censo de Solano se hallen incluidos algunos buglés entre los guaymíes. 


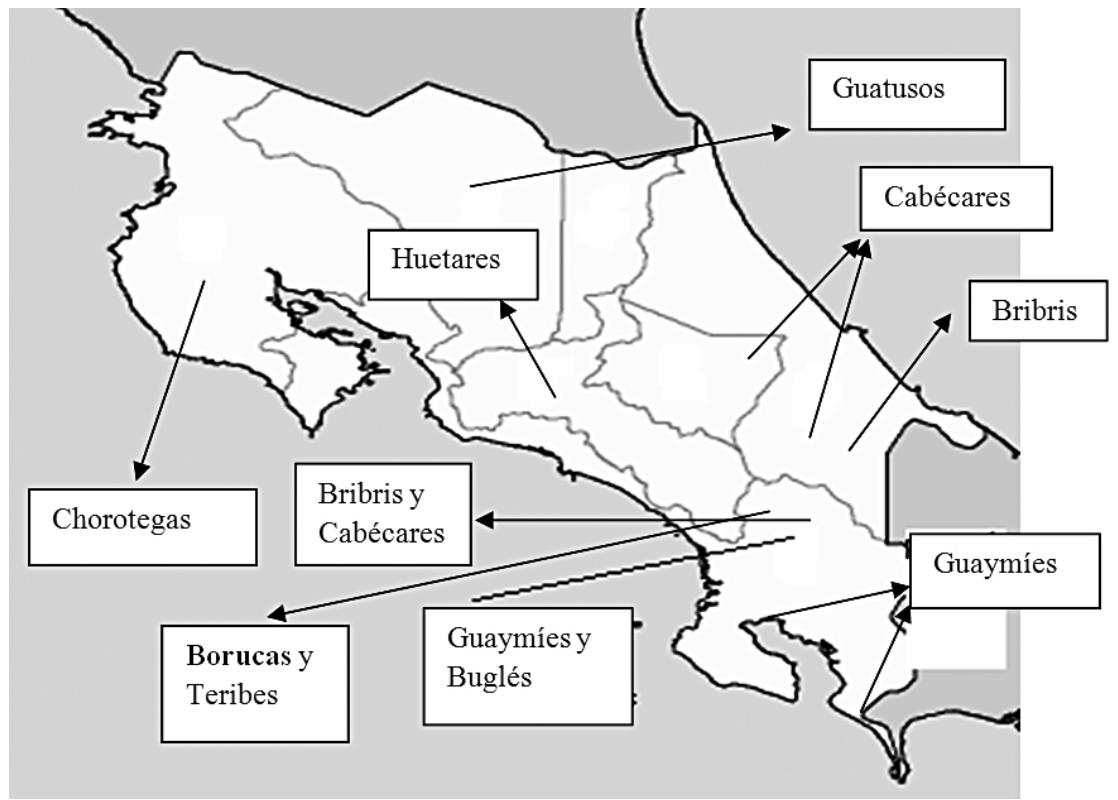

Mapa 1. Distribución geográfica de los pueblos indígenas de Costa Rica.

En cuanto a la afiliación genética de las lenguas habladas en suelo costarricense, todas pertenecen a la familia chibcha, con excepción del chorotega, de afiliación otomangue. En la Figura 1, se muestra el árbol genealógico de la familia chibcha, la cual se extiende desde el oriente hondureño, costa atlántica nicaragüense, Costa Rica, Panamá y Colombia, hasta el occidente venezolano. El miembro más occidental y norteño de la familia es el paya de Honduras y el más oriental es el barí de Venezuela. De las 24 lenguas que se han identificado como chibchas, nueve están muertas ya y otras ya están a punto de extinguirse, tales como el paya de Honduras y el guatuso de Costa Rica, las cuales tienen menos de 600 hablantes, así como el rama de Nicaragua con solo 24 hablantes; el resto comprende lenguas con números de hablantes que oscilan entre los 2,000, como el barí de Colombia y Venezuela, hasta incluso 150,000, como es el caso del guaymí en Panamá y Costa Rica. No obstante, la mayoría de las lenguas vivas tiene un promedio de 3,000 hablantes y por el momento no se ven tan seriamente amenazadas como las mencionadas arriba. Como se aprecia en la Figura 1, el tronco pota de la familia chibcha está compuesto por las lenguas rama y guatuso, habladas en Nicaragua y Costa Rica, respectivamente. Estudios sobre afiliación genética de la familia chibcha (e.g. Quesada-Pacheco 1990, 1996) colocan a la extinta lengua de los huetares dentro de este tronco. El resto de las lenguas chibchas habladas en suelo costarricense se ubican bajo el tronco ístmico.

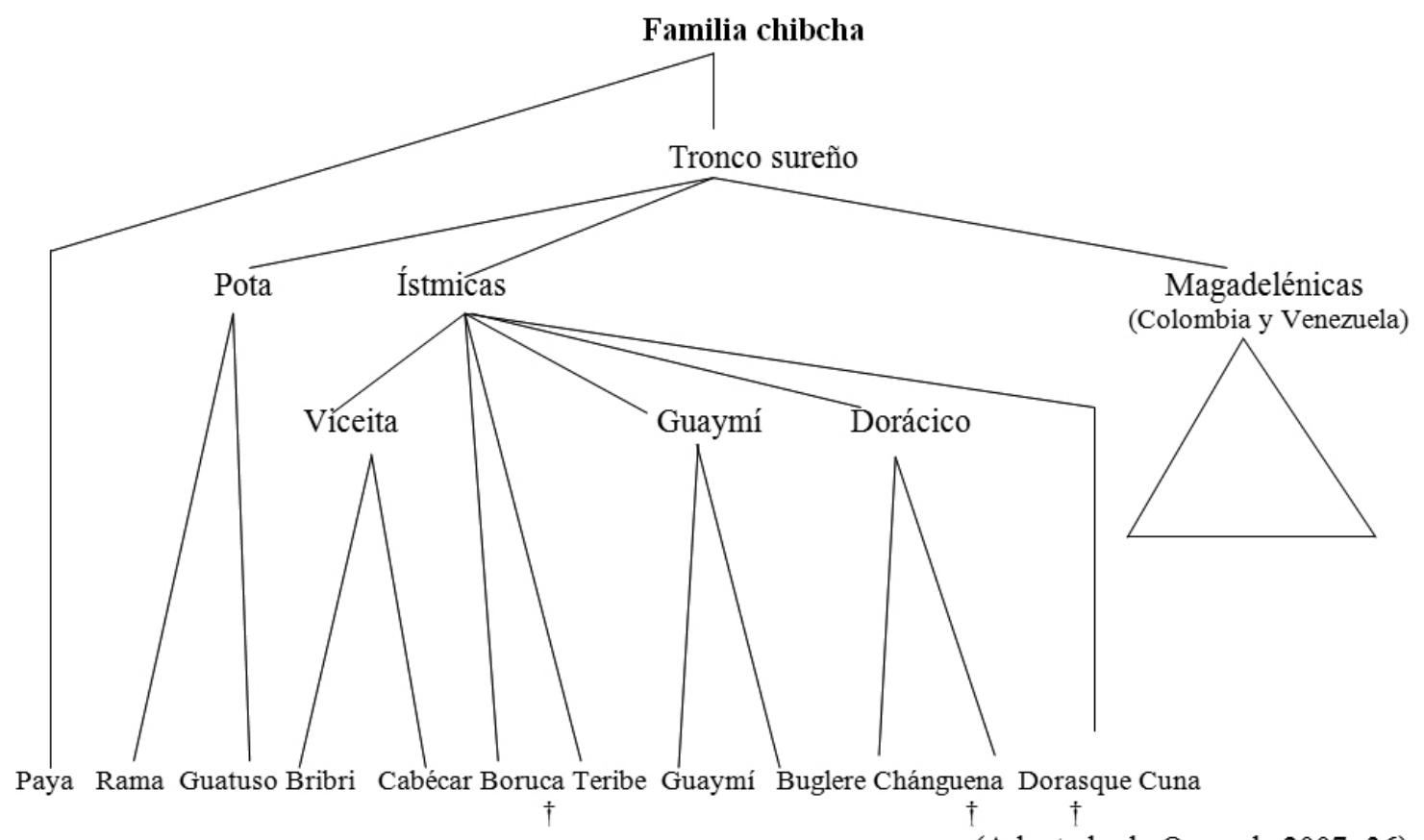

Fig. 1. La familia chibcha

(Adaptado de Quesada 2007: 36) 


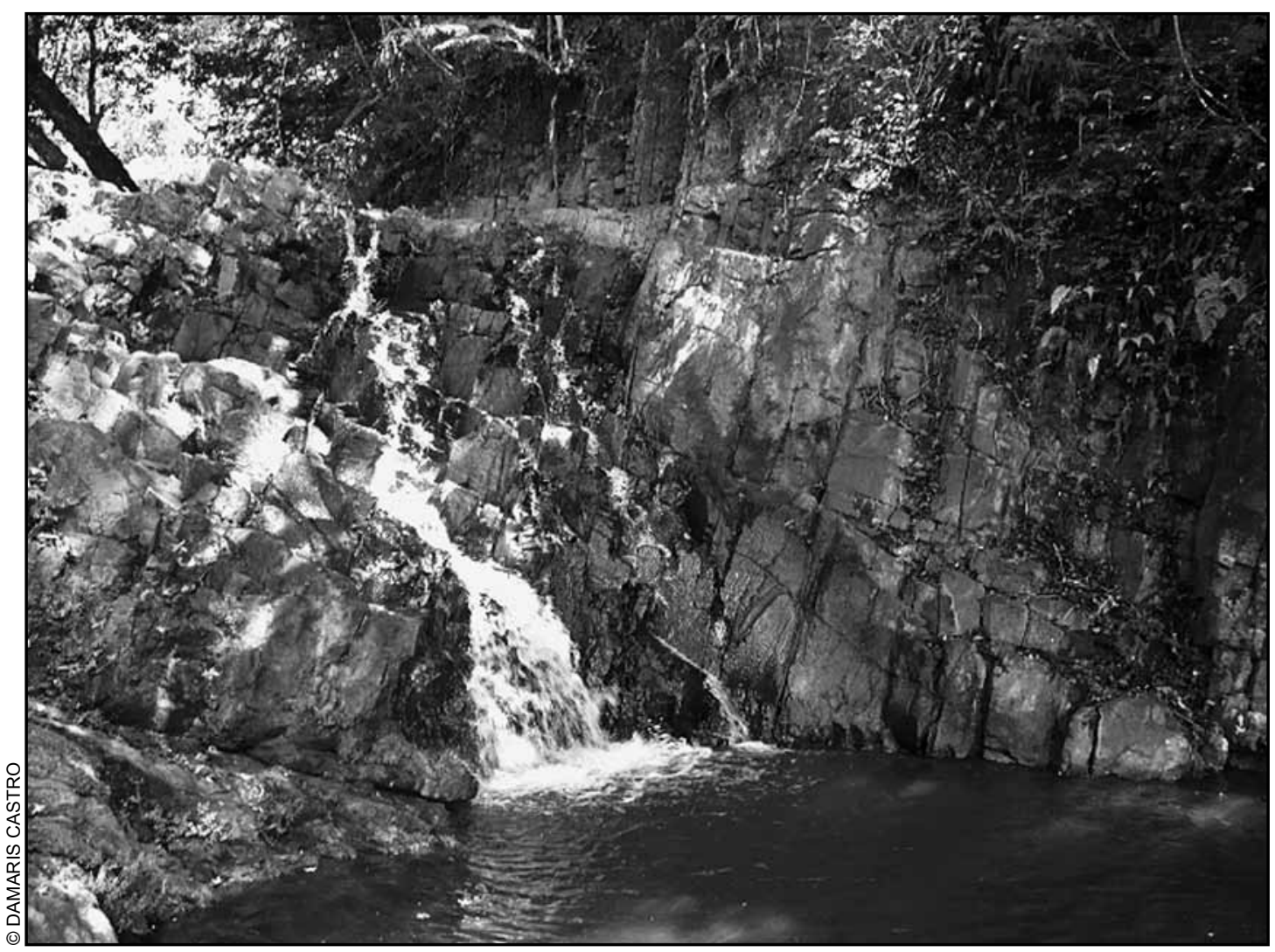

Poza de Sankrawa en Boruca. Puntarenas, Costa Rica.

En lo que respecta al estado de supervivencia, las lenguas indígenas costarricenses evidencian diversos grados de vitalidad/peligro. Existen desde lenguas extintas, como el huetar, el chorotega y más recientemente el boruca, hasta lenguas con cierta vitalidad como el bribri y el guaymí. La extinción de la primera data de mediados del siglo VIII; al ser los huetares el grupo más numeroso y poderoso que habitaba el país a la hora del contacto, fueron su cultura y su lengua las que sufrieron directamente el impacto de ese hecho histórico. En cuanto al chorotega, ésta había iniciado su declinación a principios del siglo XIX (Quirós 1999), y se consumó a mediados de ese siglo. Por último, el boruca pasó al panteón lingüístico costarricense al morir, en el año 2003, la última hablante fluida de esa lengua; en Quesada (2002) se ofrece una sinopsis de la bibliografía existente sobre el boruca. ${ }^{1}$ Otra lengua costarricense que se considera extinta es el térraba, que en realidad es un dialecto de la lengua teribe, que actualmente se habla con relativa vitalidad en Panamá (Quesada 2000). Los teribes fueron separados en 1698 por misioneros franciscanos para lograr someterlos. Un clan, conocido como térrabas, fue traído del noroeste de Panamá -en ese entonces territorio de Costa Rica- al Pacífico de Costa Rica. Luego de 300 años de separación, y prácticamente cero contacto, se dio un reencuentro entre teribes y térrabas; culturalmente huérfanos, los térrabas pronto fueron asimilados a la cultura mestiza y abandonaron su lengua; a pesar del reencuentro, ambos grupos afirman ser dos pueblos diferentes. De ambos dialectos de la lengua teribe existe una gramática, del teribe de Panamá (Quesada 2000), y del dialecto térraba (Constenla 2007).

Las lenguas vivas presentan diversos grados de vitalidad/ declinación. Procediendo de mayor a menor peligro de extinción se reseña en lo subsecuente el estado de cada una de estas lenguas. Se incluye además referencias de estudios sobre cada una de ellas, así como otra información pertinente; esta información está basada en Adelaar y Quesada (2007).

\footnotetext{
La discrepancia entre año de fallecimiento de la última hablante y la reseña de la muerte del boruca tiene que ver con la secuencia de aparición de los números de la fuente, la cual iba en ese momento con dos años de retraso.
} 


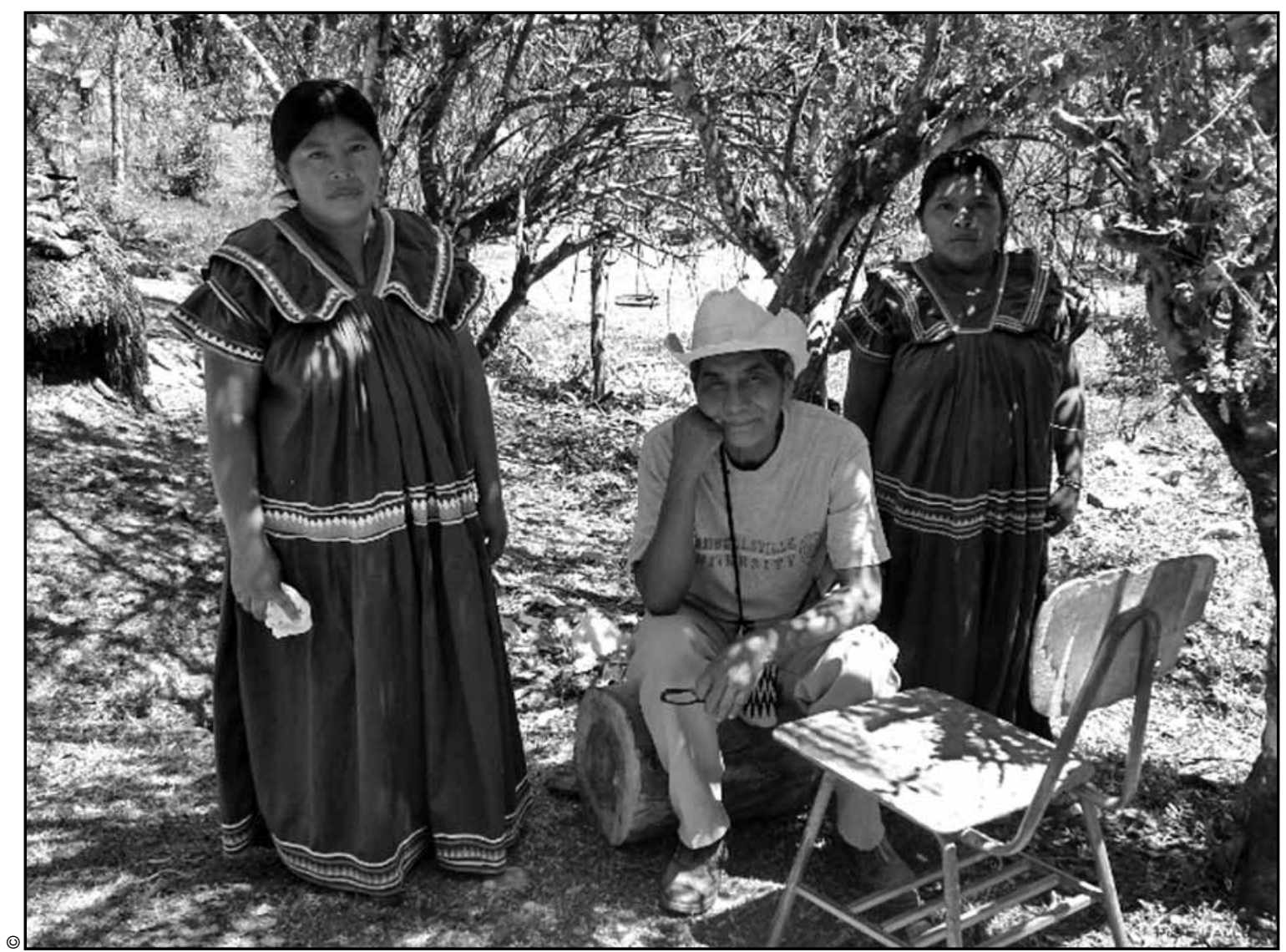

Luis Morales y sus dos esposas, las hermanas Mariela y Marlene Santos.

\section{Guatuso}

También se conoce con el nombre de maleku jlaica. Se habla en las llanuras del norte de Costa Rica, en la provincia de Alajuela. Existen tres comunidades guatusas, llamadas palenques, Tonjibe, El Sol y Margarita. La lengua está prácticamente extinta en las dos últimas. En la comunidad existe una emisora de radio, pero no se utiliza para el rescate de la lengua. Los hablantes fluidos no llegan a 300. Existe una gramática de esta lengua (Constenla 1999).

\section{Buglere}

También se le conoce con los nombres de guaymí sabanero, bocotá y bocotá de Chiriquí. Esta lengua es originaria de la provincia panameña de Veraguas; en esa comunidad la lengua se conoce como bocotá; el buglere es un dialecto del bocotá. Como se señaló anteriormente, los buglés emigraron de Veraguas a la provincia panameña de Chiriquí, donde iniciaron la coexistencia con los guaymíes. En los años 80 del siglo pasado, una cantidad emigró a la zona sur de Costa Rica; actualmente conviven en la Reserva Indígena
Guaymí, en Limoncito, cantón de Coto Brus, Provincia de Puntarenas. En su diáspora, los buglés han perdido muchas de sus costumbres y han sido asimilados por los guaymíes, más numerosos y culturalmente más fuertes. Incluso existe un bilingüismo unidireccional de parte de los buglés, quienes, independientemente de su género, al unirse con los guaymíes adoptan esa lengua; lo inverso no ocurre. Este fenómeno se da también a lo largo de la reserva, no solo en uniones maritales. Está en vías de publicación una gramática de esta lengua (Quesada, en prensa).

\section{Bribri}

Es una lengua con relativa vitalidad. Se habla a ambos lados de la cordillera de Talamanca, en las provincias de Puntarenas y Limón, existiendo variantes dialectales determinadas por este hecho geográfico. Si bien, no existe una gramática como las del teribe, el térraba, el guatuso o el buglere, sí existen descripciones sobre aspectos de su estructura gramatical, textos para su aprendizaje (Constenla et al. 2004; Jara \& Segura 2008), lo mismo que narraciones (Jara 1993), así como textos de naturaleza etnolingüística (Segura \& Jaén 1996), entre otros. 


\section{Cabécar}

Es la hermana más cercana del bribri, cuyo grado de separación se ha estimado en tan solo 1,100 años (Constenla 1995: 28). Al igual que el bribri, tiene dos dialectos, determinados por su ubicación a ambos lados de la cordillera de Talamanca. Es la única lengua costarricense que posee hablantes monolingües. Actualmente está en proceso de elaboración una gramática de esa lengua por parte de un equipo de investigadores alemanes, adscritos al Programa Lenguas Indígenas de la Baja Centroamérica (PROLIBCA); véase más adelante. Existe, sin embargo, un diccionario cabécar-español que contiene un esbozo de algunos aspectos de la gramática de esa lengua (Margery 1989).

\section{Guaymí}

También se le conoce como ngäbére, ngäbe y movere. Es la lengua de la familia chibcha que posee el mayor número de hablantes, aproximadamente 150,000. La mayoría de ellos vive en Panamá, donde la lengua tiene gran vitalidad; en Costa Rica viven unos 2,500, cuya presencia en el país data de mediados del siglo pasado. Existe una gramática de la lengua guaymí hablada en Panamá (Quesada-Pacheco 2008) y actualmente en preparación se encuentra una del dialecto costarricense (Murillo, en preparación). Es la hermana más cercana del buglere.

El estado en general de estas lenguas es de peligro latente. A pesar de que existe un programa de educación indígena en el Ministerio de Educación, según el cual, las lenguas se enseñan en las comunidades, la realidad es que el efecto positivo es poco; educación bilingüe como tal no hay y la lección de lengua materna es impartida por hablantes y a veces semi-hablantes que no tienen entrenamiento en pedagogía. Ese problema se podría contrarrestar si la lengua se utilizara de manera natural; sin embargo, salvo muy pocas excepciones, la constante es que los maestros se dirijan a sus alumnos en español, enviando el mensaje implícito de que la lengua de importancia es el español. En Costa Rica, el estatus de reserva solamente garantiza derechos territoriales (y a veces ni siquiera eso, como lo demuestra el hecho de que dentro de las reservas hay colonos mestizos); la tradiciones culturales se toleran, pero existe una política velada de asimilación, mediante la cual el gobierno busca crear una nación culturalmente unificada (cfr. Rojas Ms). El



Javier, informante indigena guaymí, con su prima. Puntarenas, Costa Rica. 
entrabamiento artificial al proyecto de Ley de Autonomía de los Pueblos Indígenas que la oligarquía costarricense ha hecho a través del poder legislativo, y el cual lleva ya más de quince años, es tan solo una muestra de tal política.

En las instituciones de educación superior, UCR y UNA existen programas de investigación sobre las lenguas indígenas; estos son el INIL (www.inil.ucr.ac.cr) y PROLIBCA ( www.literatura.una.ac.cr/prolibca), respectivamente. Existe también una revista especializada en estas lenguas, Estudios de Lingüística Chibcha, publicada por la UCR. Con la creación de la Asociación
Centroamericana de Lingüística ACALING, se espera dar mayor impulso al estudio de estas lenguas, mediante proyectos conjuntos de investigación, de revitalización e intercambio de varios tipos. Por ejemplo, quienes investigan el rama podrían acercarse a los chibchólogos costarricenses; de igual manera, la experiencia nicaragüense en educación intercultural bilingüe podría ser de gran beneficio para los costarricenses. Próximamente se reabrirá el Doctorado en Cultura Centroamericana en la UNA, el cual incluye una mención en lingüística centroamericana. Es decir, la mesa está servida para la integración lingüística en la región.

\section{Bibliografía}

Constenla, Adolfo. 1995. "Sobre el estudio diacrónico de las lenguas chibchenses y su contribución al conocimiento del pasado de sus hablantes". Boletín del Museo del Oro 38-39: 13-55.

. 1998. Gramática de la lengua guatusa. Heredia: EUNA.

2007. La lengua de Térraba. San José: Editorial Universidad de Costa Rica.

Constenla, Adolfo, Feliciano Elizondo \& Francisco Pereira. 2004. Curso Básico de Bribri. San José: Editorial de la Universidad de Costa Rica.

Jara, Carla. 1993. ITTE: Historias bribris. San José: Editorial de la Universidad de Costa Rica.

Jara, Carla \& Alí Segura. Aprendamos la lengua Bribri. San José: Editorama.

Margery, Enrique. 1989. Diccionario cabécar-español/español-cabécar. San José: Editorial de la Universidad de Costa Rica.

Murillo, José M. (en preparación). Gramática del guaymi de Costa Rica.

Quesada, J. Diego. (en prensa). Gramática del buglere. Cartago: Editorial Tecnológica. .2000. A Grammar of Teribe. Munich: Lincom-Europa. . 2002. “Adiós boruca: Sibu ki ba wi'ra moréng”. Estudios de Lingüística Chibcha 20-21:55-64. 2007. The Chibchan Languages. Cartago: Editorial Tecnológica.

Quesada, J. Diego \& Willem Adelaar. 2007. "Meso-America". Encyclopedia of the World's Endangered Languages. Moseley, Christopher [Ed.]. Nueva York: Routledge: 197-209.

Quesada-Pacheco, Miguel. 1990. “La lengua huetar”. Estudios de Lingüística Chibcha 9: 7-64. 1999. Los huetares: historia, lengia, etnografia y tradición oral. Cartago: Editorial Tecnológica. . 2008. Gramática de la lengua guaymí (ngäbe). Munich: Lincom-Europa.

Quirós, Juan S. 1999. Diccionario español-chorotega/chorotega-español. San José: Editorial Universidad de Costa Rica. Rojas, Carmen. (MS). “La enseñanza de las lenguas indígenas en Costa Rica”. San José: Ministerio de Educación.

Segura, Alí \& Alejandro Jaén. 1996. Ies Sa’Yilite. Los ojos del alma. San José: Centro Cultural Español/Agencia Española de Cooperación Internacional.

Solano Salazar, Elizabeth. 2000. La población indígena en Costa Rica según el censo 2000. http://www.ccp.ucr.ac.cr/ noticias/simposio/pdf/solano.pdf. 